range ${ }^{1}$, a poor rater might have his score weighted by $1 / 9$. If raters were to use the more common 20 point scale, weighting factors could be more extreme.

Robert T. Hodgson

Professor Emeritus, Humboldt State University email: bob@fieldbrookwinery.com

\title{
References
}

Goldstein, Robin, Johan Almenberg, Anna Dreber, John W. Emerson, Alexis Herschkowitsch and Jacob Katz. (1980). Do more expensive wines taste better?. Journal of Wine Economics, 3(1), $1-9$

\section{Wine Valuation Analysis}

Here is recent convergence of Science and economics. Physicists from the Centre National de la Recherche Scientifique determine a dating method for the glass of a wine bottle.(1) An investigator at the meeting of American Association of Wine Economists presents evidence that famous old empty wine bottles are rapidly increasing in market value.(2) While it cannot be determined whether this temporal concordance is causal, it should be noted that testing of the bottle and invasive testing of wine are already being offered by Antique Wine Company.(3)

James J. O'Donnell, M.D. Professor Emeritus, UC San Francisco email: JOdonn5952@aol.com

\section{References}

(1) http://www2.cnrs.fr/en/1283.htm Paris, September 1, 2008 Vintage wine bottles authenticated by high energy ion beam. Just like works of art, wine is now being subjected to advanced testing to establish its authenticity: after measuring caesium 137 radioactivity levels to test the age of the wine, the glass in vintage wine bottles is now being tested by particle acceleration. Referred by Barbara O'Donnell.

(2) http://www.wineeconomics.org/meetings/Portland2008/details.htm Portland, Oregon, August 14-16, 2008, Second Annual Conference of American Association of Wine Economists (AAWE), as described by Professor Orley Ashenfelter, President, AAWE.

(3) http://www.antiquewine.com/press_room_article.php?press_room_id=38

1 Maximum score less minimum score 